\title{
Supply Chain: Systematic Literature Review to Define Critical Strategies to Achieve Flexibility in Health Sector
}

\author{
Hanan Qatawneh, PhD \\ Assistant Professor \\ AlYamamah University \\ Riyadh, Saudi Arabia
}

\begin{abstract}
Recognizing the importance of achieving supply chain flexibility in this dynamic environment, this research explores the critical strategies that can be applied to achieve supply chain flexibility in health care. The research design, guided by a Qualitative philosophy, was inductive in nature. Using different journal articles in the areas of uncertainty, flexibility, supply chain management, supply chain flexibility and health care management, a number of different strategies to facilitate supply chain flexibility in health care were deduced. The challenge for health care supply chain leaders and health professional is to develop and apply 1. proactive strategies, that is developed and employed through 2. effective whole supply chain communication, and 3. continuous organizational learning. Supply chain managers can potentially benefit from this research that added a new perspective to fit the agility exist in the market place. The proposed strategies improve flexibility in the networked health care supply chain.
\end{abstract}

Keyword - Supply chain management, Supply chain flexibility, Health care Management, critical Strategies, Proactive strategy, Communication, Organizational learning

Paper Type - Research Paper

\section{Introduction}

Supply chain is the lifeblood of an organization that links suppliers, producers, and final customers in a network to create and deliver products and services to the customers (Stevenson, 2012). It is the involvement of different entities in the upstream and downstream that affect the flows of products, services, finances, and/or information from a source to a customer (Mentzer et al., 2001). Organizations are operating in a very dynamic environment, changes in both external and internal context of any organization is happening in a very fast pace. Supply chains are becoming more complicated and the ability to sense and respond rapidly, easily, predictably, and with high quality will become increasingly critical as the complexity, instability, and competitiveness of global markets continues to grow (Hofman and Cecere, 2005).Nisula (2012) say that strategic flexibility, collaboration, willingness to change and networking capabilities are necessary characteristics for interaction within this dynamic environment.Healthcare supply chain is complex, as it is consisting of merged professions, that includes physicians, nurses, pharmacists, managers, administrators, suppliers and other stakeholders each with different perspectives and roles within this networked supply chain. The degree of change in healthcare is accelerating, not slowing and the influential forces that are transforming healthcare can generate vast economic potential for those who are able to employ different techniques in the short term and at the same time plan for success in the long term (Al-Abri, 2007). Health care supply chain all over the world is facing continuous changes; patient wider expectations and desire for variety and change, new ways of treatments, new medical discoveries and scientific advances, new ways of managing, new rapidly evolving technologies and new learning opportunities. Despite that, the reality of the performance of this sector is quite different and is characterized by long waiting times, inefficiency, low productivity, stressed medical staff and dissatisfied patients (Purbey et al., 2007).Managers are realizing health care is not doing as expected. The question that arose is with this continuous change what to do to improve health care delivery? How hospitals can meet and even exceeds the requirements, needs and expectations of their patients? Swinehart and Smith (2005) say that health organizationslooking for gaining a sustained competitive advantage must develop the necessary operational competences to improve such areas as cost, quality, delivery, flexibility, and innovation.

The diversity of demands and needs for the patient processes concerning availability and lead-times and the complexity in production planning due to uncertainty requires different process strategies to fully describe and design a health care supply chain (Aronsson et al., 2011). Health care organizations needs to apply different strategies that mitigate the changes in the external and internal contexts and that provide hospitals with a flexible direction that leads to ongoing emergence of a continually improving health care practice. 
As scholars and practitioners have researched, supply chain flexibility is one of the levers that supports supply chain operations in the face of growing uncertainties (Fayezi et al, 2014).

Upon examining existing literature from Supply chain management, supply chain flexibility and health care management it is found that agreement exist about the need for improving the supply chain flexibility as a lever to improve supply chain performance, however, studies on supply flexibility are rare and the theoretical underpinnings of the concept of supply flexibility have not yet been well developed (Lao et al, (2010) and Fayezi et al. (2014). Different studies approached that objective differently. Some studies in the literature emphasized internal organizational flexibility while others focused on the interaction of the whole supply chain. Most of the studies were conducted in manufacturing sector and very few in service sector. Yi et al., (2011) conducted an exploratory multi-case study, involving five Chinese companies in the textile and apparel industry, aiming to examine the different flexibility strategies adopted by supply chain participants as a result of different environmental uncertainties. Another study by Lao et al, (2010) conducted were data collected from 201 manufacturing firms indicated strong, positive and direct relationships between supply management practices and supply flexibility, and between supply flexibility and supply chain performance. Fayezi et al. (2014) based their study on an analytical process for the assessment of uncertaintyflexibility interactions which provides the basis for quantification of the flexibility gap within supply chains.

The literature contains frameworks, models, and illustrations from a variety of theoretical and organizational contexts while no frameworks or models of supply chain flexibility are unique to healthcare organizations. Because health care is such a complex system, it is incredibly difficult to capture its richness in any one model (VanVactor, 2013). This study differs than previous ones as it is exploring critical strategies and factors that can be applied to achieve supply chain flexibility in health care.

In this paper, the researcher first presented a brief definition and discussion of supply chain flexibility. Following that the researcher discussed briefly importance of improving supply chain flexibility within health care connected network of relationship and described current problems that affect the success of health care service and delivery. To answer the objective of the study, a literature review was then presented to reflect the most critical strategies and factors that are needed to facilitate supply chain flexibility. Finally, conclusions and future direction was presented.

\section{Supply Chain Flexibility}

To understand supply chain flexibility, there is a need to explain the meaning of flexibility. Flexibility is a very broad concept, it comprises diverse aspects of an organization. Reviewing the literature, there is no one single definition for supply chain flexibility. Lao et al, (2010), Yi et al. (2011) and Fayezi et al. (2014) defined flexibility as the capability of a firm to respond to unanticipated environmental changes in its operating environment, production process and in the marketplace. Li et al. (2008) in their literature review found that there is inconsistency in the usage of flexibility, adaptability, and responsiveness as dimensions of supply chain agility. For example, they mentioned that Goldsby et al. (2006) explain that flexibility is the key for a supply chain being able to provide agile response. Evans and Lindsay say that to achieve performance excellence and agility "Organizations must have the ability to respond quickly and flexibly to changing customer needs, wants and desire and in response to other internal factors and changes in the business environment" (2011, P. 446). Agility in other studies also been referred to the ability to compete within a state of dynamic and continuous change (Sarkis2001 and Aronsson et al., 2011).

As within the literature scholars used the following terms as interchangeable (responsiveness, flexibility, adaptability, agility, sustainability), and there is a lack of consistency on the relationships between these concept, the researcher will focus in this paper on the flexibility concept, and defined supply chain flexibility in health care as the ability of health care organizations to adapt and respond to the constantly changing global competitive health care environment to deliver innovative service to their patients in a timely, high quality and cost-effective manner.

There have been considerable international concerns about hospital performance in patient care and quality that needs to be improved as been reported in international health care studies (Leggat et al., 2011). Unpredictable uncertainties in the health care supply chain can arise from both external and internal sources. Aronsson et al. (2011) say uncertainties might relate to the time for performing a task during the operation which may vary depending on unforeseen complications, uncertainties due to delays caused by personnel unavailability in time, delayed arrival of patients, preparations that have not been done correctly. Further added that these uncertainties are genuinely unpredictable and must be handled by flexibility."To cope with various uncertain issues, many firms are now restructuring their operational processes to better manage their environmental dynamics and to achieve competitive priority" (Yi et al., 2011).Lennox et al. (2017) say that although improvement initiatives show benefits to health care delivery, they often fail to sustain. 
What clearly emerges from the various studies of strategic flexibility is the basic outcome that the traditional strategic management objective of choosing one "best" design of action is likely to be an unrealistic objective in an uncertain environment (Sanchez, 1997).

As health care sector is operating in a volatile environment with too much variability within both external and internal environment of the hospital, defining a rigid systematic process to achieve flexibility in health care context would be impossible. Therefore, this Study does not provide a systematic model or framework on how to achieve supply chain flexibility. Rather, it provides critical strategies to achieve that effectively and successfully. These strategies and factors are not applied in a certain sequence to guide health professional on what to apply first, however the factors and strategies are too important to be considered and might be held as part of important component of different models exist in literature for effective supply chain management.

Healthcare supply chains have been described as highly fragmented and complex, showing inadequate enhancements in cost and quality over the years (McKone- Sweet, Hamilton, and Willis 2005; Nachtmann and Pohl 2009; Schneller and Smeltzer 2006) cited in (Abdulsalam, 2016). The fit between environment and elements of strategy has been stressed in the management literature, Anand and Ward (2004) emphasized that firms must match the type of flexibility pursued with the nature of environmental dynamism they face. Based on that, in this research the researcher deduced three critical strategies that is built according to the health care environmental dynamism which is characterized as complicated volatile and fragmented sector.

\section{Research Methodology}

As per the findings of Sanchez (1997) and Ward (2004) mentioned above, and through systematic literature review in the areas of uncertainty, flexibility, supply chain management, supply chain flexibility and health care management, the researchers in this study deduced the following main critical strategies that provides managers with a new lens to achieve supply chain flexibility effectively in health care context. Managers need not to neglect other factors mentioned in the literature but focus first in the proposed critical strategies been deduced. From a practical angle, this study illustrates how different health care supply chain participants need to focus on the proposed strategies and factors to restructure their organizational different supply chain nodes to manage different environmental uncertainties to achieve better health care delivery.

\section{Discussion}

Below are grounding theories and relevant literature review that led to the deduction of the proposed three critical strategies.

\subsection{Proactive strategies}

"Concern about patient safety, caused in part by high-profile major failures in which many patients have been harmed, is rising worldwide" (Walshe and Shortell, 2004, P103). Health care organizations are facing different problems including avoidable errors, underutilization of services, overuse of services and variation in services (Evans and Lindsay, 2011). Herzlinger (2006) say that although health care advancement is made over the years but effectiveness in the delivery and treatment of health care is not achieved. In health care delivery there is a gap between the supply of and demand for quality health care which requires major changes in preventing or delaying illness and death by crafting inexpensive and cost-effective interventions that take advantage of the scientific knowledge and advancement available (Zepeda, 2012).

Traditional organizational strategies adopt reactive approach to improve organizational performance. In today'seconomy this strategy is not enough. As per the study of Li and Barnes (2008), it is encouraged that organizations implement proactive risk management methods that mitigate risks by reducing the possibility of a negative event occurrence and/or eliminating risk sources to prevent the occurrence of a negative event. To achieve customer satisfaction, loyalty, and customer driven supply chain requires a proactive approach that is based on gathering data about customers to learn their needs and preferences and then providing products and services that satisfy the customers' needs (Foster, 2010). Proactive manager plans ahead, makes changes before problems occur, maintains contact with people in the organization's environment and values the change process (Sander, 1990). In health care there is a need to adopt proactive strategies to assess both external and internal health care supply chain uncertainties. Hospitals' managers must move from a reactive to a proactive management approach to anticipate, and even predict, changing needs and wants rather than continuing to react to symptoms and emergencies. Desouza et al (2008) say that it is vital that organization innovate continuously and consistently. Successful organizations take advantage of customer-driven innovation to further their growth, enter new markets and be leaders in their marketplace. 
Maddox (1987) emphasized that employees need to evolve new understandings of problem-solving and holistic methods of analytical and creative problem-solving to deal with future, unique, and uncertain problems which are not manageable with problem-solving strategies and techniques that have worked well in the past."The traditional leadership practices currently used have proven ineffective to guide healthcare leaders through the complex and dynamic healthcare challenges of today (Longenecker \& longenecker, 2014; Vaughn et al., 2014; Weberg, 2012) cited in (Waldvogel, 2014, P.7).

Stevenson and Spring (2007) explored through their study that the impact of merging a flexible supply chain strategy with means of proactively minimizing unwanted supply chain uncertainty, an aspect overlooked in many previous studies. There is a need that individuals spark initiative and guide their own creativity, rather than simply react to fires burning out of control (Phelan, 2001). There is a need to engage in life-long learning to identify and capitalize on opportunities that bring about meaningful change (Chiaburu et al., 2006).Identifying supply chain risks which disrupt the performance and the severity of their impact on the supply chain can help an organization design effective supply chain networks and decide the right supply chain risk mitigating strategies that mitigate the adverse effects due to these risk sources" (Punniyamoorthy et. al., 2013).Evans and Lindsay (2011) emphasized the use of (Failure Mode and Effects Analysis) tool as a proactive method for evaluating a process to identify where and how it may fail and to assess the relative impact of different failures, in order to identify the part of the process that are most in need of change. Organizations can combine failure mode and effect analysis with a supply chain risk management process to enhance the manufacturer's confidence in its supply chain design decision, and to enable the firm to proactively manage its supply-side risks (Tummala et al, 2014). Health professionals and experts need to predict different failure modes in health care system and delivery specially that can result in severe damage or death. They need to design the right actions to eliminate and reduce the risks of that failure. Hospitals' managers must move from a reactive to a proactive management approach that anticipate, and even forecast, changing needs and wants rather than continuing to react to symptoms and emergencies.

\subsection{Collaborative efforts}

The concept of coordination has been discussed widely in the literature. Within organizations, actions carried out by one division in a system can directly or indirectly affect the actions or outcomes of another division in a system which requires coordination mechanisms that are employed to manage these dependencies between these different systems(Wilson and Platts, 2010).In today's dynamic and competitive manufacturing environment, labour flexibility and teamwork are considered as central pillars to achieve flexibility and have high effect on manufacturing environment (Fraser, 2010).

To alleviate supply risks and develop competitive advantage, supply professionals need to synchronise the relationships in the supply chain and increase the flow of information and communication efforts(Larry et al., 2004).Craighead et al. (2007) explained that a more flexible reaction to supply chain disruption, and the faster important information about it is communicated, the more time the supply chain would have to protect itself from the negative effects of the disruption and the less severe a supply chain disruption would likely be occurring.

Health sector involve numerous actors across the supply chain, were they are jointly responsible for supply chain effectiveness and efficiency (Abdulsalam, 2016). The structural complexity of health care organizations (Leggat et al., 2011;Zeng 2011; and Abdulsalam, 2016), and the hierarchic decision-making with the multiple conflicting goals by doctors and managers makes health care supply chain management more challenging. Van Vactor (2013) say that it is too challenging to change a large, complex, institutionally-based, bureaucratic health care system into one that encourages cross-functional, multi-disciplinary communication and problem solving. In the past, the quality of health care has been the sole responsibility of the individual health care provider. Which now is changed from a profession of individuals to one of a medical industry where health care providers will be compared, rated, and challenged to maintain or improve the quality of their product (Otto, 2005).

Weiner et al. (2005) emphasized that inadequate communication with patients and among providers is a major impediment to achieving integrated health care delivery.Towards solving the problem, it is recommended to train health provider to seek and apply contextual knowledge in every medical encounter, developing the infrastructure for a central provider to acquire and share whole-care knowledge with other health providers, and eliminating the external forces that interrupt physician-patient and inter-provider relationships. Patient inflow can be improved by process integration through the use of explicit communication paths. (Olsson and Aronsson, 2015). A critical component in business success is an established relationship between a supplier and customer built upon collaborative communication and information sharing (VanVactor, 2013). 
A doctor needs to collaborate with management and patients, management and doctors need to collaborate with medical manufacturers, health care professionals need to collaborate with external hospitals. Sinha et al. (2004) emphasized that information should be made transparent across the supply chain to help in developing an integrated network. To achieve that the organization needs to design, control and improve different strategies to facilitate that collaborative efforts and integration. Lin and Zhou (2011) clarified that when there is lack of collaboration and sharing of information among different supply chain roles to make it visible, accurate, and secure across the whole supply chain, high transactional cost, other unnecessary costs, and chaotic behavior arise.

Ramirez et al. (2013) emphasized the collaboration of multidisciplinary teams to respond to the constant change in health care and to fine-tune operations and successfully manage quality of care. And with the nature of complicated craft health care production it is required that health professionals and patients co-participate in the service delivery process (Leggat et al., 2011).Chang et al (2009) cited in Leggat et al., (2011) say that in one of the studies of 1500 clinicians found that the key components of high performance working systems such as effective teamwork, were associated with greater job satisfaction and patient satisfaction.

\subsection{Learning organization}

Health advancement are being made all the time however it is not adding value unless it is appropriately translated into health-care practice. Health professionals can easily be stuck into routines that become outdated as new knowledge becomes available. Reflecting advancement in organizational practice is not the end, there is a need to measure, monitor and adjust progress to provide guidance for future decisions. Bacal (1999) emphasized the need to improve performance even if there is no current performance problem. This provides an opportunity to help employees develop new skills and is more likely to identify barriers to better performance such as inadequate resources. Health organization needs to ensure that health professionals are skilled learner and able to adjust and adapt easily based on new signals and past mistakes. Somunolu et al (2012) in their study in health care, emphasized that due to the rapid developments and reformations, it is only possible for health organizations to achieve their goals as long as they adapt to the changes, and they continue the learning process.

Foster (2010) say that Outstanding customer service results from providing employees with outstanding knowledge and training. The above is not an easy process, to achieve it health organization needs to adopt different strategies and a well-defined method to promote the change. Evans and Lindsay (2011) emphasized that managers need to increase awareness that organizational improvement and quality is a journey that never ends and must be built on knowledge management, organization learning and adaptation to an ever-changing environment. Wen (2014) Based on Peter Senge work, emphasized learning organization concept and proposed the nature, characteristics and strategies of learning organization that aims to help the organization to adapt to the complex environment and maintain the capacity of sustainable development to include: "construct learning group of leaders; to deliver mission, stimulate aspirations and overcome self-transcendence; to learn comprehensively and change mental models; to promote deep dialogue and expand organizational capacity; to learn at work and work in learning and put learning into practice through solving problems; to eliminate the obstacles of learning and improve the effectiveness; to establish a dynamic model of learning" (Wen, 2014,P. 289). In "The Dance of Change" one of the interesting books by Peter Senge (1999)it is clarified to managers and leaders how they go beyond the first step of corporate change and shows how organization can achieve the concept of learning organization and sustain momentum.

Many studies clarified different strategies to improve organizational performance and improve organizational learning. For example, adopting new approaches for performance appraisal, employee will be encouraged to improve. Elmuti et al. (1992) say that Deming recommends replacing the traditional performance systems that encourage win-lose behavior with systems that promote co-operative and supportive behavior, where managers being highly focused on quality and long-term improvement. Further added that with this approach, organizations led to remarkable improvement in: 1. consumer recognition, 2. sales, 3. market share, 4. operating costs, 5. customer satisfaction, 6. employee morale, and 7. quality. Performance appraisals are most effective when they are based on the objective that supports the strategic directions of the organization, best practices, and continuous improvements (Evans and Lindsay, 2011).

Another way health organization can improve is through process focus and continuous examining for organizational processes from the perspective of the value they add (Krajewski et al., 2013). Leggat et al., (2011) in their study emphasized that leaders in health sector should focus on ensuring human resource management systems, structures and processes that support high performance working systems that affect health professional's performance by enhancing their knowledge/skills/abilities and commitment and by providing them with the information needed to complete their jobs. 
Molina and Callahan(2009) say that employee can make a difference in any organization through successfully coping with challenges that oppose them. Further added that through knowledge they can facilitate problem-solving which is an important methodology to foster innovation and, in turn, entrepreneurial behavior.

In one of the studies conducted in health care, it is recommended that professional organizations and health care providers can cooperate with university graduate health management education programs to prepare skilled managers in all the dimensions of sustainability and provide in-service learning experiences that integrate knowledge, skills, and abilities (Ramirez et al., 2013).

\section{Conclusion}

An empirical knowledge base about the determinants of Flexibility is still at an early stage. Despite the increasing number of publications about supply chain flexibility in the field of supply chain management, however the theoretical base for connecting and understanding supply chain flexibility is fragmented and there is a lack of consensus on what are the critical strategies to achieve that. With a more specific focus there is a few studies that reflects achieving flexibility in health care.

As health care organizations try to sustain their performance with significant uncertainties and changes in the environment, they are finding that many traditional management concepts that have worked to achieve health organizational success in stable environments do not effectively prepare health care organizations to operate successfully in this increasingly dynamic and uncertain future. Sustaining and improving the healthcare system to deliver and exceeds patients' values in this dynamic environment is a challenge that must be addressed. Both health professionals and leaders at all levels needs to support clinically-led service developments and delivery. A network of clinical and managerial supporters helps planning and achieving supply chain flexibility. As per the findings of this research, the challenge for health care supply chain leaders is to develop and 1. apply proactive strategies, that is 2 . developed and employed through effective whole supply chain communication, and 3. continuous organizational learning. Health leaders, clinicians, and health workers need to be motivated and adaptive to health care continuous changes and try with their intelligence to lead the role in improving health care.

\section{Future Direction}

While the focus of this study was on a detailed description of the three critical strategies to improve supply chain in health care, the researcher recommends further study to test, refine and fully appreciate the breadth of application of the proposed three critical strategies.

\section{References}

Abdulsalam, Y. J. (2016). A diagnosis of supply chain integration in healthcare. Available from ProQuest Dissertations $\&$ Theses Global.

Al-Abri, R. (2007) "Managing Change in Healthcare." Oman Medical Journal Volume 22(3); PP: 9-10.

Anand, G., \& Ward, P. T. (2004). Fit, flexibility and performance in manufacturing: Coping with dynamic environments. Production and Operations Management, 13(4), 369-385.

Aronsson, H., Abrahamsson, M., \&Spens, K. (2011). Developing lean and agile health care supply chains. Supply Chain Management, 16(3), 176-183.

Bacal, R., (1999). Performance Management. McGraw-Hill.

Chiaburu, D. S., Baker, V. L., \&Pitariu, A. H. (2006). Beyond being proactive: What (else) matters for career selfmanagement behaviors? Career Development International, volume 11, number 7, P: 619-632.

Chithambaranathan, P., Subramanian, N., \&Palaniappan, P. K. (2015). An innovative framework for performance analysis of members of supply chains. Benchmarking, 22(2), 309-334.

Craighead, C. W., Blackhurst, J., Rungtusanatham, M. J., \& Handfield, R. B. (2007). The severity of supply chain disruptions: Design characteristics and mitigation capabilities. Decision Sciences, 38(1), 131-156

Desouza, K., Awazu, Y., Jha, S., Dombrowski, C., Papagari, S., Baloh, P., and Kim, J. (2008) Customer Driven Innovation. To be a marketplace leader, let your customers drive. Research - Technology Management. Industrial research institute.

Elmuti, D., Kathawala, Y., \& Wayland, R. (1992). Traditional performance appraisal systems: The deming challenge. Management Decision, Volume 30 number 8, P. 42.

Evans, J. and Lindsay, W. (2011) The Management and Control of Quality, 8th ed., Thomson South-Western, Cengage learning. 
Fayezi, S., Zutshi, A., \& O'Loughlin, A. (2014). Developing an analytical framework to assess the uncertainty and flexibility mismatches across the supply chain. Business Process Management Journal, 20(3), 362-391.

Foster, S. (2010), Managing Quality Integrating the Supply Chain, 4th ed., Pearson Education, Inc.

Fraser, K. (2010). Effective teamworking: Can functional flexibility act as an enhancing factor? Team Performance Management, 16(1), 74-94.

Herzlinger, R., (2006) Why Innovation in Health Care Is So Hard. harvard business review. May 2006

Hofman, D., \&Cecere, L. (2005). The agile supplychain. Supply Chain Management Review, 9(8), 18-19.

Krajewski, L., Ritzman, L. and Malhotra, M. (2013), Operations Management: Processes and Supply Chains, 10th ed., Pearson Education, Inc.

Lao, Y., Hong, P., \& Rao, S. S. (2010). Supply Management, Supply Flexibility and Performance outcomes: an empirical investigation of manufacturing. Journal of Supply Chain Management, 46(3), 6-22.

Larry, C., G \&Reham A.E. (2004). Securing the upstream supply chain: a risk management approach. International Journal of Physical Distribution \& Logistics Management. 34 (9): 698-713.

Leggat, S. G., Bartram, T., \& Stanton, P. (2011). High performance work systems: The gap between policy and practice in health care reform. Journal of Health Organization and Management, 25(3), 281-97.

Lennox, L., Doyle, C., Reed, J. E., \& Bell, D. (2017). What makes a sustainability tool valuable, practical and useful in real-world healthcare practice? A mixed-methods study on the development of the long term success tool in northwest london. BMJ Open, 7(9)

Li, X., \& Barnes, I. (2008). Proactive supply risk management methods for building a robust supply selection process when sourcing from emerging markets. Strategic Outsourcing: An International Journal, 1(3), 252-267.

Li, X., Chen, C., Goldsby, T. J., \&Holsapple, C. W. (2008). A unified model of supply chain agility: The work-design perspective. International Journal of Logistics Management, 19(3), 408-435.

Lin, Y., \& Zhou, L. (2011). The impacts of product design changes on supply chain risk: A case study. International Journal of Physical Distribution \& Logistics Management, 41(2), 162-186.

Maddox, E. N. (1987). The Effect of ProblemSolving Strategy and outcome expectancy Cues on Creative Problemsolving Performance. ProQuest Dissertations \& Theses Global.

Mentzer, John T., William DeWitt, James S. Keebler, Soonhong Min, Nancy W. Nix, Carlo D. Smith, and Zach G. Zacharia. (2001). "Defining supply chain management", Journal of Business Logistics, 22(2): 1-25.

Molina, C., \& Callahan, J. L. (2009). Fostering organizational performance. Journal of European Industrial Training, $33(5), 388-400$.

Nisula, A. (2012). Challenges in developing organizational renewal capability in the public organizations. Paper presented at the 1-14.

Olsson, O., \&Aronsson, H. (2015). Managing a variable acute patient flow - categorizing the strategies. Supply Chain Management, 20(2), 113-127.

Otto D., (2005). Health Care and Quality Improvement. A program Evaluation Case Study. A Dissertation Presented in Partial Fulfillment of the Requirements for the Degree Doctor of Management in Organizational Leadership. University of Phoenix.

Phelan, S. G. (2001). Developing creative competence at work: The reciprocal effects of creative thinking, self-efficacy and organizational culture on creative performance Available from ProQuest Dissertations \& Theses Global.

Punniyamoorthy, M., Thamaraiselvan, N., \& Manikandan, L. (2013). Assessment of supply chain risk: Scale development and validation. Benchmarking, 20(1), 79-105.

Purbey, S., Mukherjee, K., \&Bhar, C. (2007). Performance measurement system for healthcare processes. International Journal of Productivity and Performance Management, Volume 56. Number 3, P: 241-251.

Ramirez, B., West, D. J., \&Costell, M. M. (2013). Development of a culture of sustainability in health care organizations. Journal of Health Organization and Management, 27(5), 665-72.

Sanchez, R. (1997). Preparing for an uncertain future: Managing organizations for strategic flexibility. International Studies of Management \& Organization, 27(2), 71-94.

Sander, S. I. (1990). Proactive behavior: An orientation for creating change in organizations. Available from ProQuest Dissertations \& Theses Global.

Sarkis, J. (2001), "Benchmarking for agility", Benchmarking: An International Journal, Vol. 8 No. 2, pp. 88-107

Senge P., (1999) The Dance of Change: The Challenges of Sustaining Momentum in Learning Organizations (A Fifth Discipline Resource)

Sinha, P. R., Whitman, L. E., \& Malzahn, D. (2004). Methodology to mitigate supplier risk in an aerospace supply chain. Supply Chain Management, 9(2), 154-168.

Somunolu, S., Erdem, E., \&Erdem, Ü. (2012). A study on determining the perception of learning organisation applications by health sector workers. Journal of Medical Systems, 36(6), 3925-31. 
Stevenson, M., \& Spring, M. (2007). Flexibility from a supply chain perspective: Definition and review. International Journal of Operations \& Production Management, 27(7), 685.

Stevenson, W. (2012), Operation Management: McGraw-Hill, 10th Edition.

Swinehart, K. D., \& Smith, A. E. (2005). Internal supply chain performance measurement: A health care continuous improvement implementation. International Journal of Health Care Quality Assurance, 18(6), 533-542.

Tummala, V. M. R., Schoenherr, T., C.S.C.P., \& Harrison, T. (2014). Integrating FMEA with the Supply Chain Risk Management Process to Facilitate Supply Chain Design Decisions. Production and Inventory Management Journal, 49(1), 27-73

VanVactor, J. D. (2013). Leveraging the patient-centered medical home (PCMH) model as a health care logistics support strategy. Leadership in Health Services, 26(2), 95-106.

Waldvogel, K. J. (2014). Complexity leadership: A transitional care priority. Available from ProQuest Dissertations \& Theses Global.

Walshe, K., \&Shortell, S. M. (2004). When things go wrong: How health care organizations deal with major failures. Health Affairs, Volume 23 issue 3, P: 103-11.

Weiner, S. J., Barnet, B., Cheng, T. L., \&Daaleman, T. P. (2005). Processes for effective communication in primary care. Annals of Internal Medicine, 142(8), 709-14.

Wen, H. (2014). The nature, characteristics and ten strategies of learning organization. The International Journal of Educational Management, 28(3), 289-298

Wilson, S., \& Platts, K. (2010). How do companies achieve mix flexibility? International Journal of Operations \& Production Management, 30(9), 978-1003.

Yi, C. Y., E.W.T. Ngai, \& K-L. Moon. (2011). Supply chain flexibility in an uncertain environment: Exploratory findings from five case studies. Supply Chain Management, 16(4), 271-283.

Zeng, F. G. (2011). Models for evaluation of supply chain risk with application to healthcare management (Order No. 3543620). Available from ProQuest Central; ProQuest Dissertations \& Theses Global.

Zepeda, E. D. (2012). Technology-enabled health care supply chain for primary care: Reducing disparities in the delivery of chronic care. Available from ProQuest Central; ProQuest Dissertations \& Theses Global. 